\title{
El problema del mal: la nueva teodicea como dinamizadora de la práctica cristiana"
}

\author{
Andrés Mauricio Quevedo Rodríguez ${ }^{* *}$ \\ Recepción: 4 de julio de 2018 • Aprobación: 5 de agosto de 2018
}

\section{Resumen}

La existencia del mal ha sido el punto de partida para múltiples reflexiones en torno a su origen, experiencia y sentido. Desde la teología, el problema se ha relacionado con la cuestión de la teodicea: ¿por qué Dios permite que haya mal en el mundo? La respuesta de este cuestionamiento será vital a la hora de comprender las implicaciones que tiene la revelación cristiana en la vida cotidiana. Por ende, tras elaborar las líneas fundamentales de este problema teológico, en el artículo se exponen críticamente algunas de sus soluciones clásicas. Después, se proponen distintos horizontes de comprensión para repensar la existencia del mal, en virtud, principalmente, de los aportes provenientes de la nueva teología política. Lo anterior posibilita la reflexión dinamizadora de la práctica cristiana.

Palabras clave: mal, sufrimiento, nueva teología política, teodicea, práctica cristiana, seguimiento de Cristo.

* Artículo de investigación resultado del proyecto "La teología de la cruz como horizonte crítico hermenéutico de la esperanza: perspectivas y actualización del Principium Crux", desarrollado en la Universidad de San Buenaventura. Citar como: Quevedo Rodríguez, A. M. (2019). El problema del mal: la nueva teodicea como dinamizadora de la práctica cristiana. Albertus Magnus, X(2), 85-105 DoI: https://doi.org/10.153322/5005413.5214.

** Universidad Santo Tomás, Bogotá, Colombia. Orcid: https://orcid.org/0000-0002-79156491. Correo electrónico: andresquevedor@usantotomas.edu.co 


\title{
The problem of evil: The new theodicy as a catalyst of Christian practice
}

\begin{abstract}
Existence of evil has been the starting point for many reflections on its origin, experience and meaning. From theology, the problem has been related to the question of theodicy: Why does God allow evil to exist in the world? The answer of this questioning will be vital when it comes to understanding the implications of Christian revelation in everyday life. Therefore, after elaborating the fundamental lines of this theological problem, in the article some of its classic solutions are critically exposed. Then, different horizons of understanding are proposed to rethink the existence of evil, in virtue, mainly, of the contributions coming from the new political theology. The above makes possible the dynamic reflection of Christian practice.
\end{abstract}

Keywords: evil, suffering, new political theology, theodicy, Christian practice, following of Christ.

\section{O problema do mal:}

\section{a nova teodicéia como catalisador da prática cristã}

\section{Resumo}

A existência do mal tem sido o ponto de partida para várias reflexões sobre sua origem, experiência e sentido. Da teologia, o problema tem sido relacionado à questão da teodicéia: por que Deus permite que o mal exista no mundo? A resposta a este questionamento será vital para a compreensão das implicações da revelação cristã na vida cotidiana. Portanto, depois de elaborar as linhas fundamentais deste problema teológico, no artigo algumas de suas soluções clássicas estão criticamente expostas. Então, diferentes horizontes de compreensão são propostos para repensar a existência do mal, em virtude, principalmente, das contribuições advindas da nova teologia política. O acima possibilita a reflexão catalisadoura da prática cristã.

Palavras-chave: mal, sofrimento, nova teologia política, teodiceia, prática cristã, seguimento de Cristo. 
¡Cuán narcisista tiene que ser, en el fondo, una fe que, a la vista de la desgracia y el inescrutable sufrimiento que existe en la creación, en la creación de Dios, solo quiere saber de la alegría, pero no de

los gritos proferidos ante el rostro tenebroso de Dios!

Johann Baptist Metz

\section{Introducción}

Al reconocer el mal como una experiencia de la que todos los seres humanos han participado de una $u$ otra manera, se identifica como urgente aunar esfuerzos para generar nuevas comprensiones alrededor de la existencia y de la razón de ser del mal en sí mismo. Desde allí, el teólogo estará en condiciones de aportar directamente en la formación del camino de fe de los cristianos contemporáneos. Por lo anterior, el fundamento teórico de este artículo se encuentra anclado, principalmente, en la tradición teológica más reciente. En ella se hallan autores prolijos que han enriquecido la discusión teórica acerca del mal como problema teológico. Vale decir, con todo, que dichos autores no se limitan a elucubrar acerca de las realidades supraterrenales. Al contrario, se han encargado de presentar las implicaciones prácticas que las disertaciones pueden provocar en la vida cotidiana del creyente. En este sentido, las obras citadas sirven como el andamio sobre el que se edifica el acto interpretativo del autor y de aquellos que lean el trabajo.

Este artículo pretende ofrecer algunos lineamientos que permitan guiar el actuar ético de los creyentes a partir de una nueva comprensión de la teodicea. Se concluye a partir de lo dicho que el trabajo se mueve dentro de los límites marcados por la especulación sistemática y los fundamentos del comportamiento humano recogidos en la ética. De ahí que se haga explícita la profunda relación que tienen los postulados teológicos de los autores citados con la manera en que se ha de asumir la experiencia del seguimiento de Cristo desde una perspectiva comprometida y responsable.

Se pretende, por tanto, poner a disposición un estudio que no solo recoja las impresiones de teólogos de renombre en lo que se refiere a la experiencia del mal. También se desea facilitar un trabajo que, gracias a la reflexión de corte ético-teológico que contenga, ayude a formular los principios de un nuevo modelo de discipulado que no desoiga el clamor de quien sufre. Como se puede ver, se parte de una concepción de quehacer teológico que no separa nunca el pensar del actuar. Para conseguir el objetivo propuesto, se ha optado por una metodología 
que se base en la revisión documental, el análisis y el contraste de fuentes, la reflexión crítica y la síntesis creativa. La debida articulación de estas etapas ha permitido la elaboración de un artículo que, al entenderse en conjunto, ofrece un panorama general de principios teológicos de suma importancia para abordar el tema propuesto. Al mismo tiempo, brinda la posibilidad de pensar en perspectiva ética en cuanto existe una conciencia clara de las implicaciones existenciales que toda buena teología debe tener.

Así las cosas, se ha dividido el trabajo en cinco secciones, cada una de las cuales responde a un subtema en particular. Esta división ha sido planteada a partir de lo que se ha considerado como central a la hora de desarrollar el problema de manera integral. Por tanto, tras la introducción, que permite conocer grosso modo el marco general en el que se mueve la realización del artículo, se encuentra el apartado dedicado al análisis del mal como un problema teológico. Allí, además de ofrecer un acercamiento a la noción de mal, se exploran los principales grupos en los que tradicionalmente se clasifica el mal.

Posteriormente, en la tercera sección, se elabora un sondeo alrededor de cinco respuestas al interrogante del mal, que, a pesar de que cuentan con una carga histórica e institucional muy fuerte, han sido calificadas de problemáticas. Tal cualificación obedece a la realización de un proceso crítico llevado a cabo por diversos autores que se han dado a la tarea de evaluar la pertinencia de los postulados formulados. Este interés se entiende a partir de la posibilidad de identificar modos de creer que han herido el proyecto cristiano entendido en toda su magnitud y radicalidad.

Después, se exploran tres elementos que, a juicio del autor, son necesarios para la construcción de un camino congruente tras las huellas de Cristo y sus seguidores. Esta sección ofrece de manera explícita la manera en que el cristianismo asume una postura ética frente al mal que va mucho más allá de la reflexión teórica. Es más, es absolutamente válido afirmar que aquí se logra llegar a formular los principios fundamentales, no solo para que el creyente individual asuma su opción de fe, sino para comenzar el establecimiento de un diálogo con personas que confiesan otras creencias, pero que se enfrentan igualmente a la experiencia del mal.

Para terminar, se ha dispuesto un apartado de conclusiones. En él se delinea claramente el punto de llegada al que el desarrollo del trabajo ha permitido alcanzar. Además, se reconocen sus límites, planteando de esta manera las posibilidades que existen para desarrollos posteriores. Este ejercicio facilita la autoevaluación del autor en cuanto hace posible que se coteje el objetivo propuesto con los resultados alcanzados. 


\section{El mal como problema teológico}

\subsection{Líneas generales del problema}

“Un Dios que permite el sufrimiento del inocente y la muerte absurda no es digno de llamarse Dios" (Moltmann, 1983, p. 62). Con esta afirmación radical, Moltmann sintetiza de manera dramática un problema antiguo que permanece vigente: la teodicea. Compuesta por las raíces griegas theos (Dios) y diké (justicia), la teodicea es una categoría que se refiere al intento de justificación de un Dios bueno y amoroso ante la existencia del mal en el mundo. El tema resulta ser de gran importancia, sobre todo si se piensa que la era de las comunicaciones ha logrado, tal vez como nunca, mostrar las diversas caras que el mal puede tomar (Gesché, 2010). Y esto se hace aún más llamativo cuando se reconoce que "no son pocas las personas que han optado y optan por hacer mucho daño de manera deliberada y con total salud psicológica" (Novoa, 2015, p. 51).

En efecto, la evidencia de un mundo lleno de mal ha sido el punto de apoyo en el que muchos basan su argumento para negar la existencia de un ser supremo. Dios se muestra como ausente de una historia que clama sin cesar por su presencia y que al no encontrarla se inclina por darle la espalda a la divinidad y así sepultar su posibilidad de creer. Para algunos, resulta impensable sostener la fe en aquel Dios todopoderoso que se predica bajo el epíteto de ser amor absoluto, ya que no se encuentra una respuesta adecuada a la pregunta por la relación entre Dios y el sufrimiento del mundo. Así lo dejan ver Ratzinger y Flores D'Arcais (2009) cuando, ofreciendo argumentos para abrazar el ateísmo, recuerdan el clamor que ya en su tiempo levantaban los epicúreos:

Dios, o bien no quiere eliminar los males ni puede, o puede y no quiere, o ni quiere ni puede, o quiere y puede. Si quiere y no puede, es impotente: lo que no puede ser en Dios. Si puede y no quiere, es envidioso, lo cual es igualmente contrario a Dios. Si no quiere ni puede es envidioso e impotente, y por tanto, no es Dios. Si quiere y puede, lo que solo es atributo de Dios, ¿de dónde deriva la existencia de los males y por qué no los elimina? (p. 101)

Ahora bien, la pregunta por el mal no solo sigue abierta a la espera de alguna palabra satisfactoria, sino que ella misma da origen a muchos otros cuestionamientos que concretizan la noción del mal en las agonías cotidianas: “¿Por qué los 'buenos' (o los que se dicen tales) se ven golpeados por las desgracias más frecuentemente que los 'malos'. ¿Por qué esta desigualdad? ¿Por qué estas 
guerras, estas miserias, estas hambres, estas tiranías, estas violencias?" (Morin, 1990, p. 111). Abrumados ante interrogantes de este calibre, muchos se cierran sobre sus perplejidades y sostienen la imposibilidad de decir algo frente a una realidad tan enorme, sobre todo cuando se reconoce que "son los sentidos placenteros los que mandan las conductas humanas, no los discursos de la razón noética y especulativa" (Novoa, 2015, p. 55).

Pero la actitud del teólogo, y la del cristiano en general, no puede ser de espectador pasivo y callado ante el horror del mal. Al contrario, la fe en Cristo permite que el creyente se atreva a pensar el mal y el sufrimiento que él conlleva a partir de la sabiduría misma. El acercamiento al problema de la teodicea tiene sentido, tanto a nivel especulativo como ético, gracias a que Jesús se ha constituido en la plenitud de la autocomunicación divina. Aún más, la cruz ha llegado a ser, haciendo eco de la teología joánica, el culmen de revelación de Dios al ser humano. En este sentido, "la cruz no pide en modo alguno una humilde adhesión al 'no saber' en esta ardua cuestión; viene a expresar, más bien, a la luz de la resurrección de Jesús, que ahora podemos afirmar con plena certeza que Dios y el sufrimiento ¡han de confluir en un denominador común!” (Thiede, 2008, p. 20).

Concretamente, hay que afirmar que no es sencillo ofrecer una definición de mal. Es más, la noción de mal no puede ser establecida de otra manera que no sea en relación comparativa con la noción de bien (Morin, 1990). Con todo, es posible esbozar algunas ideas que permitan acercarse a la realidad de lo maligno. El mal, lejos de ser sencillamente una categoría mental o un algo que percibimos en la cotidianidad, es una forma que la existencia tiene por el mismo hecho de ser. Puede ser entendido como el momento en el que se ve truncado aquel orden último al que el ser humano está llamado. La frustración de este fin se comprende a partir no tanto del fin en sí mismo como de la carencia y limitación de los medios que se poseen para alcanzarlo (De Sahagún, 2003). En últimas, el mal es lo no debido en cuanto su presencia lesiona profundamente la historia humana (Garrido, 2000).

\subsection{Clasificación del mal}

De manera similar a lo que ocurre con la definición del mal, su clasificación tampoco tiene una única respuesta. Al abordar el problema del mal y la teodicea, el filósofo cristiano Gottfried Wilhelm Leibniz estableció tres grupos diferentes para clasificar los diversos males presentes en el mundo (Thiede, 2008). El primero de ellos es el malum naturale, que encierra en sí mismo todo aquel sufrimiento que se genera a partir de las fuerzas de la naturaleza, sean estas externas al ser humano (catástrofes naturales) o internas a él (enfermedad, muerte). El segundo grupo es el 
malum morale, que se entiende como el resultado de las malas decisiones del ser humano durante los diferentes momentos de su vida. Por último, se encuentra el malum metaphysicum, relacionado con la imperfección ontológica propia de lo creado que se presenta antes de los dos males anteriores. Es decir, aquella condición limitada que tiene la creación por el mero hecho de ser diferente de Dios (Rahner, 2007).

Por otro lado, según algunos teólogos, el único mal que existe es el mal moral. Así lo afirma, por ejemplo, el cardenal Gerhard Müller (1998) en su compendio de teología dogmática. Para el actual prefecto de la Sagrada Congregación para la Doctrina de la Fe, la historia es el escenario donde ocurren dos actos diferentes. El primero de ellos es protagonizado por Dios y se identifica con el acto creador. El segundo está dado por la respuesta que la creatura le brinda al Creador en ejercicio de su libertad. El mal tendría su origen, entonces, en la falencia que subyace en el acto segundo en la medida en que de las decisiones humanas se desprenderían consecuencias negativas. En este esquema, no es posible catalogar, al menos teóricamente, las calamidades naturales como malas en sí mismas, puesto que la categoría mal se enmarca en lo moral, por lo que limita la disertación casi exclusivamente al ámbito de lo pecaminoso.

Si para los pensadores del grupo anterior solo era pensable hablar de mal en clave de moralidad, los autores que sostienen la clasificación en perspectiva existencial sostienen que el mal existe únicamente a partir de su aparición en la conciencia humana. Bajo esta mirada, para ofrecer un ejemplo, un terremoto es malo únicamente si su ocurrencia afecta la vida de las personas. A partir de aquí se diferencian dos clases de mal. Primero, el existencial, derivado de la naturaleza corruptible de la creatura y que se evidencia en los fenómenos naturales o la enfermedad. Segundo, el mal moral, que nace de las distintas repercusiones que tienen las decisiones de cada individuo (Morin, 1990).

De Sahagún (2003), por su parte, retoma el modelo tripartito de Leibniz para modificarlo a partir de un único eje: el sujeto. Reconoce en él tres dimensiones, a saber, la física, la psíquica y la social. La clasificación del mal entonces dependerá no solo del origen de la situación negativa, sino de la dimensión humana que se vea afectada. Así, el mal físico se presenta como la carencia de alguna propiedad material que halla su manifestación en el dolor. El mal psíquico se entiende como el fruto de diversos sentimientos que pueden confluir en conjunto o por separado: pérdida de ideales, distorsión de la identidad, sensación de fracaso o cualquier otro desajuste interior. Si como consecuencia del mal psíquico se quebranta alguna ley, entonces figurará lo que en otros ámbitos se denomina mal moral. El mal social, por último, se expresa en el desequilibrio en las relaciones interpersonales dentro de un grupo humano. 


\section{Soluciones problemáticas a la cuestión del mal}

A lo largo de la historia de la teología se han planteado respuestas ante la pregunta por la existencia del mal frente a la fe en un Dios bondadoso. Sin embargo, no todas ellas han resultado ser satisfactorias, ya que sus postulados encuentran serios problemas a la hora de ser sometidos a la crítica. Se ofrecen ahora de manera breve cinco de dichas respuestas junto con algunos de los cuestionamientos más relevantes en su contra.

\subsection{La doctrina de la retribución}

La doctrina de la retribución, que comprende el pecado como el causal del mal, encuentra sus orígenes remotos en la tradición rabínica. En el ámbito cristiano, fue adoptada por Pablo de Tarso y posteriormente por la gran mayoría de los Padres de la Iglesia. Según esta concepción, el mal y sus distintas manifestaciones en el mundo son un castigo que Dios impone movido por la ofensa de los pecados cometidos por el ser humano (Müller, 1998). La visión de un Dios castigador contiene un esquema soteriológico propio que divide la redención en dos tiempos independientes y prácticamente inconexos. Por un lado, la redención del género humano se realiza únicamente por medio de la superación del pecado gracias a la muerte sacrificial de Jesús en la cruz. Por otro, el sufrimiento y la muerte, que se ven como consecuencias del pecado, serán eliminadas solo cuando llegue la resurrección futura.

Para el cristiano, resulta incompatible la aceptación de un Dios que castiga y la fe que le indica que las lógicas divinas se mueven por la gratuidad absoluta y no por la deuda. La imagen del Dios vengativo fue superada por la noción de Padre amoroso predicada por Jesús. Además, la estrecha relación entre pecado y mal fue puesta en duda ya desde algunos escritos del Antiguo Testamento, particularmente en el libro de Job (Bravo, 2006). El interrogante que allí se levanta es claro: si el mal es castigo divino al pecado, ¿por qué sufre el justo? Se llega así a un callejón sin salida, en el que solo queda indicar que "no se puede afirmar que, de no existir el pecado, no habría sufrimiento. La experiencia del sufrimiento excede con mucho a la experiencia de la culpa y de la gracia" (Moltmann, 1983, p. 66).

\subsection{Dualismo ontológico}

Desde sus inicios, muchos movimientos religiosos rechazaron la idea monista que coloca al Ser Supremo como el origen del mal. Por eso, los sistemas de 
pensamiento como el zoroastrismo y el maniqueísmo contaban con dos orígenes subsistentes para toda la realidad: uno de ellos era la causa de las cosas buenas, mientras que el otro era el productor de los elementos negativos (De Sahagún, 2003). Esta concepción dualista llevaba a entender la dinámica universal como una búsqueda del equilibrio entre las fuerzas antagónicas del bien y del mal reflejada en fenómenos físicos como los binomios luz/oscuridad, día/noche y calor/frío. El mal pasaba a ser una parte constitutiva y necesaria del mundo en cuanto era entendido como el contrapeso del bien en la balanza del cosmos.

Ya en la época antigua, especialmente con la enseñanza de Agustín de Hipona, el cristianismo se opuso a una interpretación dualista de la realidad. A partir de los relatos primordiales del Génesis, la Iglesia sostiene que todos los seres vivientes y la naturaleza en sí misma son buenos puesto que proceden del único Creador lleno de bondad. Por ende, al mal no se le reconoce un estatus creatural, ni respecto de Dios ni respecto de otro origen eterno: "El mal no es una sustancia creada ni, por tanto, la manifestación de una cara oscura en Dios o de un principio malvado. No debe confundirse el mal con la contingencia y la finitud de lo creado" (Müller, 1998, p. 177).

\subsection{El mal como privación del bien}

El ya mencionado obispo de Hipona es uno de los primeros teólogos cristianos que entiende el mal no como una realidad ontológica determinada, sino como carencia en la participación de la naturaleza de Dios. Su afirmación se basa en el presupuesto de que todo lo creado, tanto lo material como lo espiritual, es ontológicamente bueno. Sin embargo, aclara que no todas las cosas cuentan con el mismo nivel de bondad, ya que cada una mantiene una relación de semejanza particular con el Bien Absoluto (Bravo, 2006).

El problema de esta noción, por un lado, es que puede llegar a caer en el descaro y la absurdidad: ¿cómo decirle a una víctima de cualquier clase de violencia que el mal que le atacó en sí no existe? Quitarle al mal su identidad o posibilidad de ser conlleva renunciar a atacarlo de manera directa. No hay necesidad de combatir aquello que solo se postula como una mera carencia de algo más grande. Por otro lado, la interpretación antes descrita deja abierta la pregunta acerca del medio por el que la condición biológica del ser humano podría participar de la bondad infinita de Dios para así no tener que atravesar la enfermedad. Aún más, se podría plantear un interrogante similar en cuanto a la naturaleza y a la forma de evitar los fenómenos catastróficos. 


\subsection{El mejor de los mundos posibles}

Según indica Thiede (2008), Leibniz ofrece uno de los más conocidos intentos de solución al problema del mal. Partiendo de la imposibilidad de culpabilizar al ser humano, puesto que esto estaría en contra del espíritu de la Ilustración en boga por aquella época, afirma que el mundo en el que vivimos es el mejor de todos los mundos que Dios habría podido crear. La guerra, los fenómenos naturales, la enfermedad, el sufrimiento, las masacres, los personajes oscuros y cualquier otro mal presente en la historia, a pesar de su negatividad, serían elementos que, de no existir, harían de este un mundo peor. Una realidad mejor que actual, en el pensamiento del filósofo alemán, sería imposible.

Resulta casi evidente que la principal crítica que se puede alzar en contra de la teoría de Leibniz es que ella termina siendo una justificación del mal. Si no puede existir una realidad más buena que esta, la esperanza se desdibuja a causa del conformismo que se genera ante lo inmutable. En consecuencia, la lucha en contra del mal también sería absurda. El cosmos entero caería irremediablemente en un letargo de indiferencia al aceptar el mal como algo estipulado que obliga al mutismo. Una visión de semejante talante camina en contravía del cristianismo. La fe en Jesús implica la aceptación del Reino de Dios, entendido como una realidad superior compuesta por un elemento escatológico, por el que se permanece en espera jubilosa, y un elemento presente que exige el trabajo en el aquí y el ahora.

\subsection{Búsqueda del sentido del mal}

Como paso final, se hace referencia aquí a todas aquellas corrientes que pretenden dotar al mal de significado positivo. En ellas se reconoce que la pobreza, la enfermedad, el pecado y cualquier otra clase de sufrimiento pueden no tener explicación pero sí sentido. Dicho sentido estaría dado por varias interpretaciones (Bravo, 2006). El mal puede ser entendido, entre muchas otras posibilidades, como una prueba que Dios impone para acrisolar el espíritu de la persona, un elemento de la pedagogía divina con fines de preparar a alguien para una misión importante, una corrección del cielo o un vehículo de gracia especial que permite la unión del sujeto con los padecimientos de Cristo. En un panorama así, tienen cabida expresiones como las siguientes: “¿Así que puedo dar gracias a Dios por haber pecado, sintiendo una pena inmensa por haberle ofendido? ¡Sí! ¿Así que mereció la pena tanta historia humana de sufrimiento para poder conocer tal Amor infinito? ¡Sí! ¿Así que incluso el pecado es relativo? ¡Sí!” (Garrido, 2000, p. 223). 
Los anteriores planteamientos, por más extendidos que estén en los ámbitos eclesiales, deben ser reconsiderados a la luz de las críticas que se les presentan. De aquí que se necesite con urgencia una mayor inteligencia de lo que significó la crucifixión y la resurrección (Rahner, 2007). Es tiempo de abandonar los esquemas sacrificialistas que han convertido la fe en Jesús en una religión que no se corresponde con el Evangelio, una religión en la que el dolor se constituye en el medio por el que se alcanza el favor divino (Varone, 1988). Relativizar el mal y sus consecuencias trae la acogida de una actitud estoica que se limita a soportar pasivamente todo aquello que le sobrevenga. Hay que sostener más bien que “el mal es precisamente lo injustificable. Por una parte, en el plano moral: no se justifica un acto malo; por otra, en el plano racional: no tiene ninguna razón de ser" (Gesché, 2010, p. 113).

Cabe aclarar que con lo anterior no se quiere invalidar la posibilidad de una búsqueda de sentido del sufrimiento. De hecho, se reconoce que "el asunto del sentido es de vida o muerte ya que constituye la columna vertebral de nuestra existencia" (Novoa, 2015, p. 56). Con todo, la adquisición de un sentido de vida debe permitir ir más allá de una mera autocompasión o convencimiento optimista, tal y como se verá en el siguiente acápite.

\section{El cristiano frente al mal}

\subsection{La nueva teodicea}

Numerosos pensadores actuales han tratado, en mayor o menor medida, el problema del mal. Por tal razón sería aquí imposible hacer una síntesis del pensamiento de todos ellos. De acuerdo con esto, el tercer paso de este trabajo pretende esbozar algunos elementos que animen una reflexión del quehacer del teólogo y del cristiano en general a partir de las reflexiones de teólogos contemporáneos de renombre. Evidentemente, no se pueden ofrecer más que algunas puntadas respecto de los tópicos particulares de sus formulaciones, ya que un abordaje a fondo excedería la naturaleza del artículo.

El punto de partida de las consideraciones de este apartado se concentra en alguien en concreto: Jesús. Efectivamente, aceptar la encarnación del Logos implica reconocer en la persona histórica del Nazareno una realidad humana que no escapó a la vivencia del mal. Por un lado, Jesús entiende su ministerio como una batalla férrea en contra de las fuerzas malignas que amenazan el mundo. En tal marco de referencia, hay que entender, por ejemplo, los exorcismos, las 
curaciones y los demás prodigios que narran los relatos evangélicos. Por otro, Jesús evidenció en sí mismo la experiencia radical del mal. Y esto no solo en los momentos de sufrimiento por antonomasia, es decir, el proceso de pasión y muerte en cruz. Jesús también se encontró con el mal en la frustración que supuso el aparente fracaso de su misión y en el abandono de aquellos que lo seguían.

Pero la relación entre Jesús y el mal no se limita a la evidencia de lo negativo en su historia. Más bien, es de resaltar que, en la medida en que Cristo se constituye en el hablar definitivo de Dios, "la respuesta divina al misterio del mal y del dolor no va a ser, pues, un discurso como pareciera esperar Job, sino toda una vida, la vida de su palabra hecha carne" (Ruiz de la Peña, 1988, p. 166). Por eso, resulta valioso hacer hincapié en las tres actitudes por medio de las que, según Ruiz de la Peña, Jesús responde al mal:

- $\quad$ El amor: no acepta simplemente lo bueno que hay en las personas, sino que acoge a la persona de manera completa, con sus luces y sombras.

- La fe: en medio del sinsentido que produce la crudeza del mal y el silencio de Dios, expresado en la pregunta “¿Por qué me has abandonado?” (Mt 27,46), ocurre un acto de entrega y de fe que no se genera a pesar del mal, sino a partir de él.

- La mística: lejos de ser un asceta que convierte en virtud aquello que existe como irrevocable en la historia, Jesús cree firmemente en la derrota del mal que se producirá a través de la acción divina.

Los aportes de lo dicho se convierten en el fundamento para lo que algunos autores consideran como el planteamiento de una nueva teodicea. Metz (2007), por ejemplo, propone un cambio de paradigma a la hora de abordar la pregunta por Dios ante el mal. Para él, la teodicea ya no debe ser el intento obstinado por defender la omnipotencia bondadosa de Dios ante las acusaciones que profieren las situaciones de sufrimiento. Tal empresa resulta ser inútil en la medida en que cualquier solución que se vislumbre se queda en el campo abstracto del pensamiento, pero enmudece ante los gritos proferidos por aquellos que padecen. Su experiencia biográfica, marcada por el encuentro con la muerte de sus compañeros durante el tiempo en que fue reclutado en el Ejército, le hace descubrir como excesivamente acomodado el discurso teológico-existencial sobre la fe.

La teología no puede seguirse elaborando de espaldas a los desafíos que el mal en el mundo le coloca al ser humano. Se hace necesaria una nueva teodicea que ponga su empeño en preguntarse por cómo seguir hablando de Dios a la vista del sufrimiento en el que está sumida la historia, sin olvidar la dimensión moral intrínseca a todo ser humano (Rahner, 2007). No se justifica a Dios, sino que se busca un nuevo lenguaje para poder expresar la fe de manera adecuada y 
responsable con la realidad. Pero esta modificación en el cuestionamiento no es algo accesorio que pueda ser respondido de manera unívoca. En cuanto tiene un carácter escatológico, la pregunta debe ocupar un lugar central en la teología, la que, más allá de querer hallar respuesta al interrogante, perpetuará el recuerdo y la sensibilidad por la teodicea (Metz, 2007).

Para Gesché (2010), la urgencia de una nueva teodicea es válida gracias a que el análisis clásico es insuficiente. De hecho, sostiene que las reflexiones tradicionales han querido justificar un Dios-esquema entendido desde los paradigmas filosóficos. Esto ha producido que en teología el problema del mal se haya relegado a un ámbito puramente racional que no responde a la desgracia concreta de las personas. El autor opta por recuperar la posibilidad de levantar un grito que exprese la contradicción presente en la realidad. El creyente no debe guardar silencio ante el mal que lo rodea y atosiga, puesto que su fe, apoyada en la vida del mismo Jesús, lo autoriza a elevar su clamor al cielo:

Creo que una teodicea que halla a Dios en el recoveco de su contradicción y de su escándalo es la única capaz de cumplir con su deber. Y aun cuando no lograra convencer a todo el mundo (¿acaso lo logró la otra?), tendría el mérito de oír a los hombres en el lugar mismo de sus objeciones y, por tanto, en la verdad y en su auténtico sentimiento, deteniéndose primero en nuestro sábado santo, más silencioso y muerto, en cierto sentido, que el viernes santo cuando no se había bajado "a la morada de los muertos". (p. 186)

No se puede olvidar aquí que el cristiano no es un ángel que está fuera del alcance del devenir histórico de toda la humanidad. Al contrario, es preciso recordar que, de manera esencial, el ser humano está abierto a la trascendencia, afectado por la contingencia y propenso a la fe. En este sentido, la comprensión de una nueva teodicea tiene lugar desde lo más íntimo del vivir de cada persona, ya que la relación con la búsqueda de asumir el problema del mal nace de una experiencia existencial profunda.

\subsection{El seguimiento de Cristo y el mal}

El Evangelio de Marcos pone en boca de Jesús una de las sentencias más conocidas a la hora de hablar de discipulado: "Si alguno quiere seguir detrás de mí, niéguese a sí mismo y cargue su cruz y sígame" (Mc 8, 34). La afirmación es categórica: cargar con la cruz a cuestas es un requisito fundamental para aquel que quiera ser discípulo de Cristo. Ya quedó dicho cómo la visión sacrificialista ha 
pervertido el sentido de la muerte de Jesús al limitarla a un pago de deuda entre Dios y el ser humano, pero no desveló propiamente sus causas, lo que es necesario para poder entender la exigencia que se le hace al discípulo.

¿Por qué muere Jesús? Son clásicas las miradas que buscan en la pasión la voluntad de un Dios necesitado de retribución. La acción soteriológica en tales posturas se centra exclusivamente en los padecimientos de Jesús, e ignora el resto de su vida. Sin embargo, son cada vez más las interpretaciones que apuntan a entender la muerte del Nazareno relacionada con su contexto histórico y la totalidad de su ministerio. Estos puntos de vista se esmeran en rescatar la idea del Dios Padre amoroso que no puede estar sediento de la sangre de su Hijo y la decisión de un Hijo que fue fiel a su encargo (Borg y Crossan, 2007).

Sintetizando los diferentes acercamientos críticos a la pasión, es posible afirmar que el centro de la predicación del Maestro fue el Reino de Dios en la Tierra. Tal predicación se tornó problema para el entorno religioso de la época. La molestia que generó entre las altas esferas fue tal que los notables de la sociedad decidieron matarlo. Él mismo tenía claro que esto sucedería tarde o temprano; así lo dejan ver los anuncios que hizo acerca de su futuro padecimiento, que generaron pavor entre sus discípulos. Aun así, Jesús decidió llevar su misión hasta las últimas consecuencias. El nuevo sentido que la decisión le brinda a la pasión es evidente: la causa de Cristo era tan grande y significativa que tenía pleno sentido entregar la vida por ella; la obediencia (muchas veces confundida con alienación de los sentidos) le abre paso a la fidelidad (González de Cardedal, 2001).

Ahora bien, si el discípulo está llamado a seguir a Cristo, quiere decir que recorrerá los mismos pasos que Él. La cruz ya no será cualquier sufrimiento, idea comúnmente extendida en la religiosidad popular, sino solo aquel padecimiento que es causado por defender la obra del Reino. En esta línea de pensamiento, se podrían entender las demás sentencias de Jesús que hablan sobre renuncia y muerte personal:

Negarse a sí mismo significaría romper con las propias ideas en cuanto rompan la comunión con Jesús y en cuanto ellas rompan con el proyecto de Dios [...] Negarse a sí mismo significaría no dejarse determinar por el pensamiento de los hombres sino por el pensamiento de Dios contenido en la predicación de Jesús. (Henao, 2005, p. 328)

La exigencia del seguimiento es clara: ser radical implica estar dispuestos a perder la vida. He ahí el plus que presentó el cristianismo: mostrar un estilo de vida por el que era válido llegar a darlo todo. El creyente era llamado a ser mártir, a ser testigo de Cristo en cualquier circunstancia. Así lo mostraron multitud de 
mártires que durante las persecuciones de los emperadores romanos llegaron a morir en nombre del Evangelio.

La literatura martirial (pasiones, actas y vidas de los mártires) es el conjunto de testimonios de un grupo de personas que decidieron cargar con la cruz de Cristo. Y se les menciona de manera especial por un rasgo concreto: su unión con la pasión de Jesús no fue causada por una interpretación masoquista o reparadora del dolor, sino porque, al igual que con el Maestro, la muerte los persiguió motivada por la incomodidad que generaron dentro del entorno social. En efecto, las comunidades de cristianos afectaron las dinámicas sociales que el Imperio romano tenía. No asistir a los juegos, dejar de rendir culto a los dioses y demás prácticas antirromanas hicieron que el grupo de seguidores de Jesús se convirtiera en objeto de repudio (Boff, 1987).

Se encuentra entonces una continuidad muy valiosa: Jesús el mártir del Reino que radicalmente anuncia y predica es seguido por un grupo de personas que radicalmente anuncian y predican el Evangelio. El seguimiento, pues, no consiste en acatar un conjunto de normas establecidas o de parámetros religiosos, sino que se vuelve algo ontológico, algo propio del ser, algo que abarca todas sus dimensiones. Este último rasgo brinda una luz ante la pregunta por aquellos sufrimientos que no sean consecuencia del discipulado (enfermedad, desastres).

La respuesta viene dada por un elemento que atraviesa toda la reflexión de manera implícita: la espiritualidad, entendida como la dinámica interior en la que el ser humano vive su fe. Ella misma se constituye en el momento subjetivo en que las interpretaciones pasan a formar parte de la vida personal. Desde un nuevo planteamiento antropológico, cargado con todo el simbolismo del seguimiento y la radicalidad, se acogerán los sufrimientos naturales, no como castigo o designio divino, sino como algo que hace parte de la naturaleza frágil del ser humano. No se puede obviar, debe ser evitado y acompañado desde la solidaridad con el hermano; pero incluso en él debe haber oportunidad de encuentro con Dios. El Hijo de Dios, constituido tal a partir del bautismo, no será nunca legitimador del sufrimiento (Crossan, 1996).

\subsection{El combate contra el mal}

Cabe afirmar que la nueva teodicea y la teología misma, no puede sin más abandonar su aparato metafísico. La fe en el Dios cristiano no elimina el esfuerzo por la comprensión intelectual. Antes bien, necesita estar articulada por la experiencia profunda de Dios y la elucubración fundamentada de dicha experiencia. Sin embargo, es imperante que la metafísica cristiana se ancle en la historicidad del 
acontecer humano. Solo así los presupuestos dogmáticos tendrán algo que decir a las víctimas del mal (Metz, 2007). Por eso, no se deben descartar los esfuerzos de aquellos teólogos que han elaborado una explicación del origen del mal. Baste recordar, por ejemplo, el esfuerzo realizado por Torres (1986) al retomar con detenimiento la noción de mal metafísico y llevarla más allá al postular a Dios como el antimal.

A partir de la aparición de la nueva teodicea, se hace posible repensar la teología para que deje de ser discurso que se haga con los ojos cerrados frente al mal. Si la pregunta por Dios y el mal se coloca como el andamiaje para la elaboración de una teología fundamental, entonces la atención será fijada en la salvación del ser humano como víctima del mal y no tanto en su pecado (Metz, 2007). En este sentido, no basta comprender a Dios como sorprendido ante el mal presente en la bondad de su creación. Hay que avanzar un poco más para sostener firmemente que el ser humano también se sorprende cuando se encuentra de bruces con lo maligno (Gesché, 2010). Tal noción conlleva una liberación de la culpabilidad: hay algo más allá de lo propiamente humano que es negativo y que afecta la realidad (Bravo, 2006).

Como consecuencia, la conciencia del cristiano debe permitirle cambiar su manera de ver la historia. La fe sensible a la teodicea deja atrás los sueños míticos y optimistas que pretenden ignorar el mal que inunda la vida. Rahner (2007) reconoce que una de las características de la actitud cristiana es cierta clase de pesimismo que mueve al creyente a aceptar el mundo como carente de una condición superior. A la persona de fe "el cristianismo no le obliga a ver con luz optimista esta realidad de su mundo experimental, de su experiencia histórica de la vida. Por el contrario, le obliga a ver esta existencia como obscura, como amarga, como dura, como amenazada radicalmente en una medida impensable" (p. 464).

La mirada propia del seguidor de Jesús ha de mover al destierro a las imágenes falseadas de Dios. Cuando se descubre que Dios realmente está en contra del mal y que rechaza de forma radical las situaciones de sufrimiento, se ponen en tela de juicio aquellas teologías que colocan sus bases en la prosperidad material. Creer no puede ser sinónimo de estar bien de acuerdo con los paradigmas socioeconómicos que la sociedad actual promulga. La fe entonces se ha de entender de manera distinta:

¿Para qué sirve, entonces, la religión, para qué sus oraciones? Pedir Dios a Dios: tal es, a fin de cuentas, la información que Jesús da a sus discípulos acerca de la oración (cf. Lc 11, 1-13). Jesús, para ser exactos, no ha prometido ningún otro tipo de consuelo. En cualquier caso, el consuelo bíblico no nos transporta a un reino mítico de armonía exenta 
de tensión y perfecta reconciliación con nosotros mismos. El Evangelio no es ningún catalizador que ayude a la persona a encontrarse a sí misma. (Metz, 2007, p. 38)

Dentro del contexto descrito, la oración no será concebida como un acto privado que tiene por objetivo el aislamiento de la realidad. Al contrario, su papel se entiende como la capacidad que tiene el creyente de hacer manifiesto el compromiso con el mundo desde su relación con Dios. Se plantea la oración como la posibilidad de todo libre, entendiendo que la libertad "no es la facultad de poder hacer esto o lo otro, sino la de decidir sobre sí mismo y hacerse a sí mismo" (Rahner, 2007, p. 59).

La oración cristiana se inserta en la historia como el puente que une dos dimensiones. Por un lado, grita a Dios con la confianza en una actuación divina que comunicará la justicia. Por otro, brinda al creyente la fuerza necesaria para situarse en la sociedad en una forma novedosa y efectiva. En palabras de Metz y Rahner, "orar es, en realidad, un acto de resistencia. Orar es resistir a la trivialidad aplastante de nuestra vida, es oponerse a la idea de que la vida carece totalmente de objeto en una sociedad de puro cambio y necesidad, en la que decrece la capacidad de llorar y reír" (1979, p. 32). Se ha de resaltar entonces la atención que se le debe prestar al contexto histórico en el que se desenvuelve cada cristiano. Se resalta aquí con claridad el hecho de que hay un mal que está más allá de los meros principios de la responsabilidad personal, pues tienen que ver con la estructura social que de por sí es ya pecaminosa.

El cristiano, entonces, no puede quedarse incólume ante el sufrimiento que cotidianamente se le presenta con uno u otro rostro. Su posición ha de entenderse como radicalmente opuesta a las expresiones del mal. Así, la praxis solidaria llega a ser el medio por el que cada persona encarna adecuadamente el conjunto de creencias que lo sostienen y fundamentan. La actitud profética ante el sufrimiento, marcada tajantemente por el ofrecimiento incluso de la propia vida, es la concreción de la escucha de la voz del Maestro y del subsiguiente anuncio a las naciones. Es más, el combate contra la oscuridad del mundo es la mejor evangelización, ya que gracias a ella el mensaje de Jesús, marcado por la persecución y el sufrimiento como consecuencia de su opción radical por el Reino, se hace verdad y vida (Metz, 2007).

\subsection{Perspectiva escatológica}

La lucha contra el mal ocupa todas las dimensiones temporales de la historia humana. En cuanto al pasado, se espera la justicia a favor de todos los difuntos que se han perdido en el anonimato y en la impunidad. La recuperación de la 
memoria debe llevar a que, en el proceso de establecimiento del Reino de Dios, los muertos sean recordados y honrados en justa medida. La desaparición de los que gastaron su existencia por hacer un mundo mejor y de los que sufrieron el horror de la miseria humana debe tenerse presente tanto en el hoy terreno como en el mañana escatológico. Por eso, según Metz y Rahner, "se ha de pensar en los pequeños, en los despreciados, en aquellos que, aparentemente sin importancia ninguna, muertos tempranamente, sucumbieron sin dejar un nombre para la ciega crueldad de la historia" (1979, p. 97).

Respecto del presente, la lucha no conoce miramientos a la hora de vivir su radicalidad. Los que caminan tras las huellas del crucificado se deben oponer a las cruces que la sociedad ha impuesto (Ruiz de la Peña, 1988). Una fe integral conlleva la aceptación de una mirada crítica, que, a su vez, trae consigo un actuar comprometido que busca la modificación de estructuras de sufrimiento y opresión. La religión no es un opio que aparta al individuo del entorno en el que está inmerso, sino que lo capacita para ser motor de cambio. "No se trata de hablar, sino de luchar y combatir. Esta es la verdadera respuesta de la teología al problema del mal, un problema que no soporta ninguna justificación, sino un combate y una victoria" (Gesché, 2010, p. 192).

En lo referente al futuro, la noción de esperanza permite fundamentar y articular las otras dos dimensiones temporales. Se reconoce que el triunfo de Dios frente al mal y al sufrimiento de la Creación se efectuó ya con el misterio pascual de Cristo. Sin embargo, el creyente confía en que un día, ojalá no muy lejano, Dios se presentará como el plenamente victorioso (Bravo, 2006). Este rasgo escatológico, resumido en la expresión "ya pero todavía no", es la identidad que el cristianismo otorga como ligamento entre el creer y el actuar. Así las cosas, la persona de fe "confiará ciertamente en la promesa del Dios vivo y por así decir saltará desde sí mismo hasta ella, hasta la promesa de que Dios vence con su amor poderoso en medio del riesgo de la existencia" (Rahner, 2007, p. 465).

Después de lo recorrido, resulta valioso retomar las palabras de Ruiz de la Peña respecto de la relación entre el seguidor de Cristo y el mal:

La fe cristiana imprime al tema un sesgo rigurosamente inédito. El mal no es problema a solucionar antes [las cursivas son mías] de creer en Dios; el mal es la situación en que Dios se nos ha revelado tal cual es; como aquel que lo vence asumiéndolo solidariamente y transmutándolo en semilla de resurrección. El mal deja así de ser un problema soluble teóricamente para convertirse en un misterio a esclarecer vivencialmente. (1988, p. 173) 
Se vislumbra entonces salir al encuentro del otro como una manifestación de las relaciones que tendrán lugar en el Reino venidero. La lucha tradicional entre egoísmo y alteridad, a partir de la que desembocan los actos tanto negativos como positivos, hallará su culminación con el regreso del Señor. Por eso, "enamorarse y fascinarse por la alteridad y sus valores, por el otro [...] se convierte en el corazón mismo del auténtico proceder humano" (Novoa, 2015, p. 64). Cobra sentido así la sentencia de Metz y Rahner respecto de la oración cristiana: "la oración puede y debe ser el comienzo de una renovación de la esperanza, de una rebelión contra la creciente desesperanza y la lenta desaparición de todo compromiso que, poco a poco, nos va envolviendo a todos. Por eso aquella antiquísima oración de los cristianos es también hoy actual: ‘Ven, Señor Jesús' (Ap 22, 20)” (1979, p. 36).

\section{Conclusión}

Después de la presentación de algunos aspectos introductorios al mal en perspectiva teológica, de la exposición crítica de cinco intentos clásicos de respuesta al problema y de la formulación de varios elementos que ayudan en la construcción de una nueva actitud frente a la teodicea, se evalúan ahora ciertos límites y posibilidades que tiene este trabajo. Se da por sentado que el objetivo propuesto en un primer momento se cumple cabalmente en cuanto se han explorado los ámbitos delineados en la introducción. Así pues, se busca abrir puertas más que cerrarlas, con el fin de motivar ulteriores desarrollos de los elementos presentados en los párrafos anteriores.

Referente a los límites, es necesario notar que, por su intencionalidad propia, el artículo puede no profundizar como se quisiera en las diferentes aristas que tiene el mal como tema teológico. Empero, se considera que los argumentos insinuados son suficientes para que el lector se apropie de los elementos más básicos del problema para después continuar con el abordaje de literatura especializada. En segundo lugar, hay que señalar que resultaría conveniente un rastreo más exhaustivo de las diversas teologías contemporáneas que pretenden responder a la cuestión del mal. Cabe destacar, entre muchos otros autores, los esfuerzos de Jürgen Moltmann con sus reflexiones alrededor del Dios sufriente, los aportes de François Varone en perspectiva crítica a la religión y las reflexiones del ya mencionado Andrés Torres Queiruga.

En cuanto a las posibilidades, se debe resaltar la apertura al fortalecimiento del diálogo entre las teologías europeas y las teologías latinoamericanas. Es sabido que, en algunos ambientes, el quehacer teológico de tipo sistemático y 
especulativo, tan marcado en la metodología del viejo continente, ha sido fuertemente cuestionado. Con la acusación de ser ajeno a la realidad concreta del ser humano y al desarrollo real de su historia, se pondera sobre él los movimientos de liberación nacidos en América Latina tras la conclusión del Concilio Vaticano II.

Es de notar, entonces, que la perspectiva de los autores trabajados en el cuarto paso no se aleja de la vida cotidiana del creyente, sino que se presenta como una palabra dirigida nada más y nada menos que en el diario vivir de los cristianos. Se entrelazan entonces varias intencionalidades de ambas teologías que facilitan el enriquecimiento mutuo. Así, conocer más profundamente la obra de los teólogos latinoamericanos es una urgencia que debe ser atendida. Acercarse a esta literatura permitirá un mayor provecho de los recursos disponibles en las universidades del continente.

Por otro lado, a partir de la concepción que tiene Metz acerca de la cuestión de la teodicea como eje base en la construcción de la teología fundamental, vale la pena repensar todo el edificio teológico. El esfuerzo de formular un lenguaje apropiado que permita seguir hablando de Dios considerando el sufrimiento humano hace perentorio revisar los postulados de los diferentes tratados de la teología. La adopción de una teología fundamental con sensibilidad hacia la teodicea postula un reto a los pensadores cristianos a la hora de elaborar sus disertaciones: todas ellas han de estar transidas por la urgencia de responder a la existencia del mal desde la responsabilidad y el compromiso.

Otra de las posibilidades del artículo está dada por la revisión de algunas costumbres y discursos sostenidos en muchos sectores de la Iglesia. Se hace referencia aquí a aquellos esquemas de pensamiento que ponderan el dolor como medio eficaz para alcanzar la salvación o alguna clase de bien material. Queda claro que el mal y el sufrimiento que de él se desprende no pueden ser justificados o aceptados bajo ningún concepto. Al contrario, el mal debe ser combatido en todos los niveles, es decir, tanto desde lo conceptual y lo teórico como a partir de la praxis efectiva en medio del mundo.

Finalmente, hay que subrayar que las ideas presentadas buscan, en último término, propiciar que la articulación entre teoría y práctica se refleje en una espiritualidad renovada. Con esto no se insinúa que el papel del cristianismo ante el sufrimiento tenga un carácter intimista limitado a la vivencia de una religiosidad personal. Más bien, la propuesta se enraíza en la convicción de que la espiritualidad es el motor del actuar creyente en medio de un mundo cada vez más necesitado de algún faro que le indique el camino hacia tierra firme. 


\section{Referencias}

Boff, L. (1987). Jesucristo el liberador: ensayo de cristología crítica para nuestro tiempo. Santander, España: Sal Terrae.

Borg, M. y Crossan, J. D. (2007). La última semana de Jesús: el relato día a día de la semana final de Jesús en Jerusalén. Madrid, España: PPC.

Bravo Lazcano, C. (2006). El problema del mal. Bogotá, Colombia: Pontificia Universidad Javeriana.

Crossan, J. D. (1996). Jesús: biografía revolucionaria. Barcelona, España: Grijalbo.

De Sahagún Lucas, J. (2003). Dios, horizonte del hombre. Madrid, España: Biblioteca de Autores Cristianos.

Garrido, J. (2000). El conflicto de Dios hoy: reflexiones pastorales. Santander, España: Sal Terrae.

Gesché, A. (2010). El mal. Salamanca, España: Sígueme.

González de Cardedal, O. (2001). Cristología. Madrid, España: Biblioteca de Autores Cristianos.

Henao Mesa, J. A. (2005). Discipulado y cruz en el Evangelio de Marcos. Cuestiones Teológicas, 32(78), 217-329.

Metz, J. B. (2007). Memoria passionis: una evocación provocadora en una sociedad pluralista. Santander, España: Sal Terrae.

Metz, J. B. y Rahner, K. (1979). Invitación a la oración: solidaridad en el dolor y el compromiso. Santander, España: Sal Terrae.

Moltmann, J. (1983). Trinidad y Reino de Dios. Salamanca, España: Sígueme.

Morin, D. (1990). Para decir Dios. Navarra, España: Verbo Divino.

Müller, G. (1998). Dogmática. Barcelona, España: Herder.

Novoa, C. (2015). Acerca del acaecer del mal. Bogotá, Colombia: Pontificia Universidad Javeriana.

Rahner, K. (2007). Curso fundamental sobre la fe: introducción al concepto de cristianismo. Barcelona, España: Herder.

Ratzinger, J. y Flores D’Arcais, P. (2009). ¿Dios existe? Bogotá, Colombia: Planeta.

Ruiz de la Peña, J. L. (1988). Teología de la creación. Cantabria, España: Sal Terrae.

Thiede, W. (2008). El sentido crucificado. Salamanca, España: Sígueme.

Torres Queiruga, A. (1986). Creo en Dios Padre: el Dios de Jesús como afirmación plena del hombre. Santander, España: Sal Terrae.

Varone, F. (1988). El dios "sádico": ¿ama Dios el sufrimiento? Santander, España: Sal Terrae.

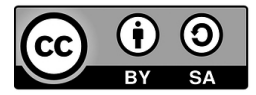

